\title{
A CENTURY OF WORKS ON RIVER SEVESO: FROM UNREGULATED DEVELOPMENT TO BASIN RECLAMATION
}

\author{
GIANFRANCO BECCIU ${ }^{1}$, MATTEO GHIA ${ }^{2}$ \& STEFANO MAMBRETTI ${ }^{1,2,3}$ \\ ${ }^{1}$ DICA, Politecnico di Milano, Italy \\ ${ }^{2} \mathrm{MM}$ SpA, Italy \\ ${ }^{3}$ Wessex Institute of Technology, UK
}

\begin{abstract}
The story of the river Seveso is briefly presented in this article. Seveso is a small river that enters into a large city as Milano, where it flows covering a total reach of around $15 \mathrm{~km}$. In the years the river produced an impressive number of floods (on average more than 2.5 per year), and no rapid solution is devised. Structural solutions have been carried out, and they are related to the construction of five storage tanks, the rehabilitation of few critical points within the covered reach of the river Seveso and the doubling of a bypass in the northern area of the province of Milano. Although it is difficult to compare the global costs to 'solve' the problem with the advantages obtained during the development of the city, in the authors' opinion the only reason for this situation is the unconsciousness of the Public Administration of that time regarding the consequences in the underestimation of the risk of floods. While structural solutions have to be quickly produced in order to alleviate the discomfort of the people living in that area, more long-term solutions should imply a change of paradigm, being mainly non-structural, more holistic and paying attention to water use and discharge destination.

Keywords: development, regulation, river Seveso, urban flood
\end{abstract}

\section{INTRODUCTION}

Floods are among the most damaging natural hazards and are likely to become more frequent, more prevalent and more damaging in the future due to the effects of increase in population, urbanization, land subsidence and to a certain extent the impacts of climate change.

According to Munich-Re [1], flood is 'a temporary condition of surface water (river, lake, sea) in which the water level and/or discharge exceed a certain value, thereby escaping their normal confines'. Problems with floods and flooding are strongly related to population, population density and the improvement of the standard of living [2].

In large cities, such as Milano, unregulated development produces frequent floods, whose consequences are high costs both for recovery after the events and for trying to produce effective solutions [3].

In the article, the story of the river Seveso is reconstructed; this small river flows into the city of Milano, and it has been covered during the years, especially in the 1950s and 1960s, i.e. during the so-called Italian economic boom, when 'development' and 'construction' were the keywords that did not allow any discussion or uncertainties. The problems that the people had to face during these years because of frequent floods led the authorities to find solutions, which are presented in the article together with the related costs.

The carried out solutions are effective in the short term, but to cope up with these hazards, it is imperative that human society adopts an effective flood risk management approach, which has to be in harmonious coexistence with floods. In practical terms, the chance of flooding can never be eliminated entirely. However, the consequences of flooding can be mitigated by appropriate behaviour and actions. To be effective, the hazard approach must be embodied in the broader context of integrated river basin planning and management, and flood must be regarded as one of the many issues involved in the appropriate management of a river basin. 


\section{POSITION OF THE PROBLEM}

In the north of the city of Milano (Italy), an area is very frequently flooded. On the date we are writing, in 140 years we had 342 floods (i.e. 2.4 per year) and they are 108 since 1976 (i.e. 2.6 per year). They are frequent, but often limited (although it is difficult to accept such a number of floods per year in a town of a self-proclaimed civilized country). However, large floods have also happened: one of the worst floods we registered was on 18 September 2010, when major damages, in addition to destroyed cars and flooded garages and shops, were recorded on subway line 3. There was great damage to the whole structure, including technological installations and bays. The consequence was the interruption of service between four stops of the subway for 10 days, and among them were the main railway station; one station had accumulations of debris and mud up to a height of 6-7 m leading to strong discomfort of citizens and inevitable repercussions on traffic. There was also serious damage to the subway M5 yards, which was still under construction. The damage delayed the opening of the new line for 2 months. The overall damages only for this event have been estimated to 20 million Euros. Moreover, in 2014 two more main events have occurred, producing discomfort in an area even larger than usual (see Fig. 1).

In the construction of subway line 5, a peculiar solution has been developed, as reported in Fig. 2. The solution is quite simple; to enter in the station, before going downstairs, the user has to climb three steps upwards: that difference in elevation allows a certain safety as the water level is expected to be below the elevation of these three steps. This 'solution' obviously implies that (i) there is flood, (ii) it is frequent and especially (iii) the solution is not to be expected shortly.

\subsection{Catchment characteristics}

This river is surely not one of those that might be known in Italy if not for the number of floods and damages it causes in Milano.

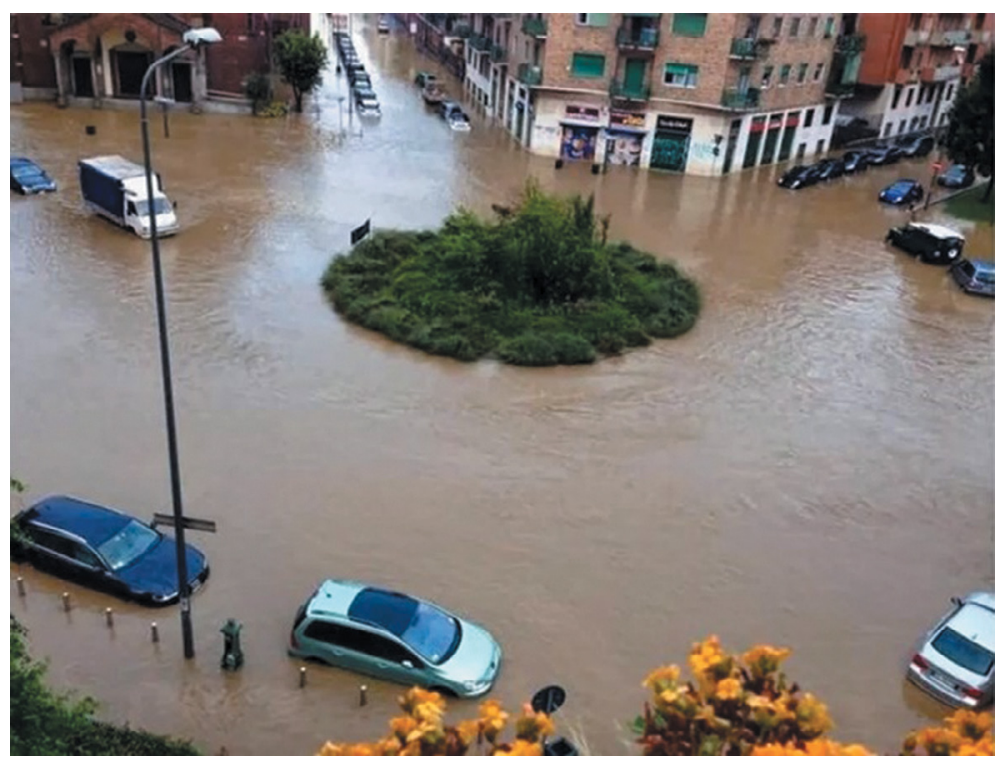

Figure 1: Flood in Milano, due to river Seveso, on 14 July 2014. 


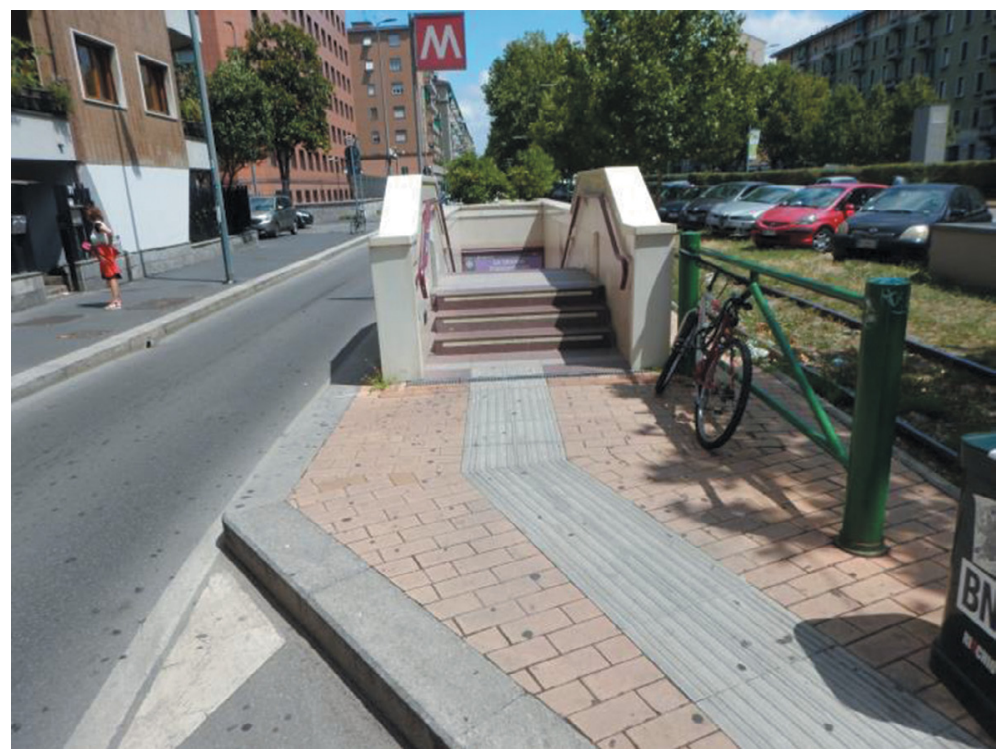

Figure 2: Entrance of subway line 5.

It originates from Monte Pallanza, in the province of Como, and flows into Naviglio della Martesana near via Carissimi in Milano. It has a total length of about $52 \mathrm{~km}$. It enters the territory of Milano municipality, where it starts to flow through covered meadows for about $7 \mathrm{~km}$. Then, as mentioned, it flows into the Naviglio della Martesana which in turn enters Canale Redefossi, forming a covered system with a length of about $15 \mathrm{~km}$ (see Fig. 3).

The Seveso catchment at the entrance of Milano has an area of approximately $226 \mathrm{~km}^{2}$, of which about $155 \mathrm{~km}^{2}$ includes the mountain basin, quite steep, that develops almost entirely in the territory of the province of Como; while the remaining $75 \mathrm{~km}^{2}$ constitutes the valley basin, which is part of the province of Milano. In the latter part, the river is flowing almost horizontally and looks like an artificial canal. About $100 \mathrm{~km}^{2}$ includes urbanized areas.

Moreover, the river collects more waters than its natural catchment, as at least three more towns (Cinisello Balsamo, Cabiate, Meda), not directly connected to any river, discharge into Seveso.

With regard to the discharges [4], the project of the authority is based on an event with 100 years of return period $\left(T_{\mathrm{R}}\right)$. In the upstream section of Seveso, flow rate values evaluated through hydraulic analysis range between 25 and $80 \mathrm{~m}^{3} / \mathrm{s}$; these values are reduced to about $60 \mathrm{~m}^{3} / \mathrm{s}$ in the intermediate part as a result of flooding, and then it remains almost constant around $65 \mathrm{~m}^{3} / \mathrm{s}$, again because of local flooding, at the end of the stretch, up to Carimate, a town in the middle of the catchment. In the downstream section, from Carimate to Milano, peak flow rates evaluated through hydraulic analysis, for $T_{\mathrm{R}}=100$ years, range between 65 and $87 \mathrm{~m}^{3} / \mathrm{s}$ in the beginning; these values increase to $158 \mathrm{~m}^{3} / \mathrm{s}$ downstream of the confluence of the Certesa River (the main affluent of Seveso), and reach the value of $165 \mathrm{~m}^{3} / \mathrm{s}$ immediately upstream of the CSNO (Canale Scolmatore di Nord Ovest). Downstream CSNO, due to the subtraction of $30 \mathrm{~m}^{3} / \mathrm{s}$ currently operated by the channel, the flow rate in Seveso for $T_{\mathrm{R}}=100$ years is reduced to $135 \mathrm{~m}^{3} / \mathrm{s}$, and then it remains almost constant, reaching Milano with discharge values of about $140 \mathrm{~m}^{3} / \mathrm{s}$, despite the large floods throughout the development of the stretch. 


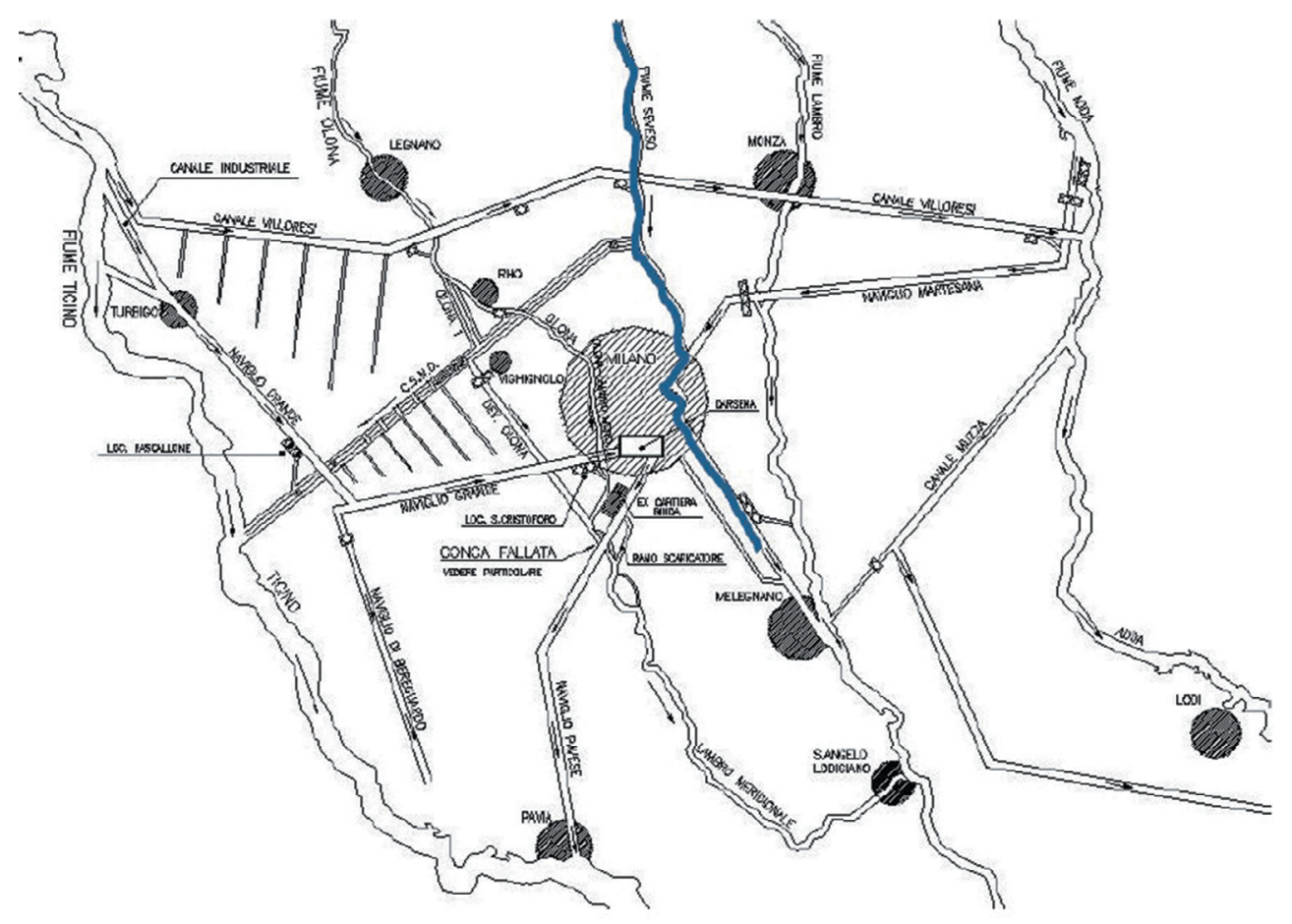

Figure 3: The complex system of canals in Milano - the river Seveso is highlighted.

As following analysis will show, in Milano the maximum allowable discharge is in the range of $35-45 \mathrm{~m}^{3} / \mathrm{s}$.

\subsection{A bit of history}

Seveso was the first river that Romans diverted to Milano; its natural course was led to touch the city on its eastern side, so that in the Republican era, the waters were further captured to the north to exploit the slight slopes of the territory and were directed to Milano through a new channel called 'Sevesetto', in order to feed the pit in defence of the city walls [5]. Many centuries later, when the construction of Naviglio della Martesana was finished (1471) and when its waters were brought to Milano (1496) the two streams intersected.

However, the water load on Milano in the event of concomitant floods of Seveso and Martesana had become excessive and it was felt that there was a need to create a channel that could unload them before they came in, and that was called Redefossi (between 1783 and 1786) [6] (Fig. 4).

Seveso cover in Milano took place gradually, with the expansion of the city. The first works date back to the end of the 19th Century, while the followings were a consequence of the General Regulatory Plan of the city of 1953.

After the Second World War, Milano developed impressively (Fig. 5), and rivers that in the past were considered to flow in the province of Milano, quite far from the town, were included in the boundaries of the town: namely, Olona in the west and Lambro in the east (Fig. 3). This outcome obviously worsened the already critical capacity of the drainage system to deal with 


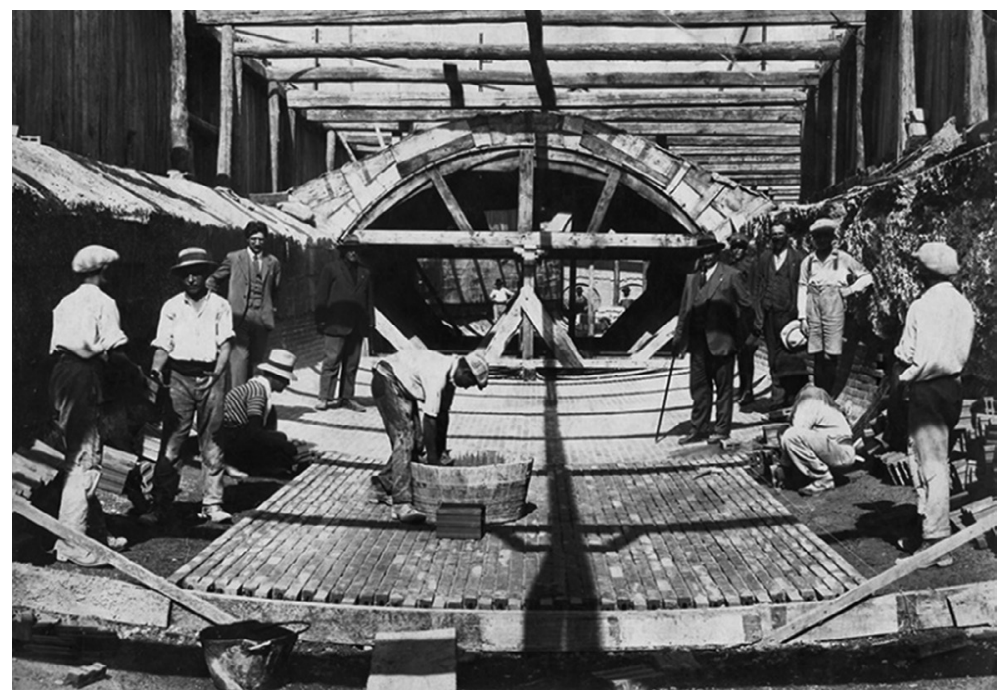

Figure 4: Covering Canale Redefossi, 1911.

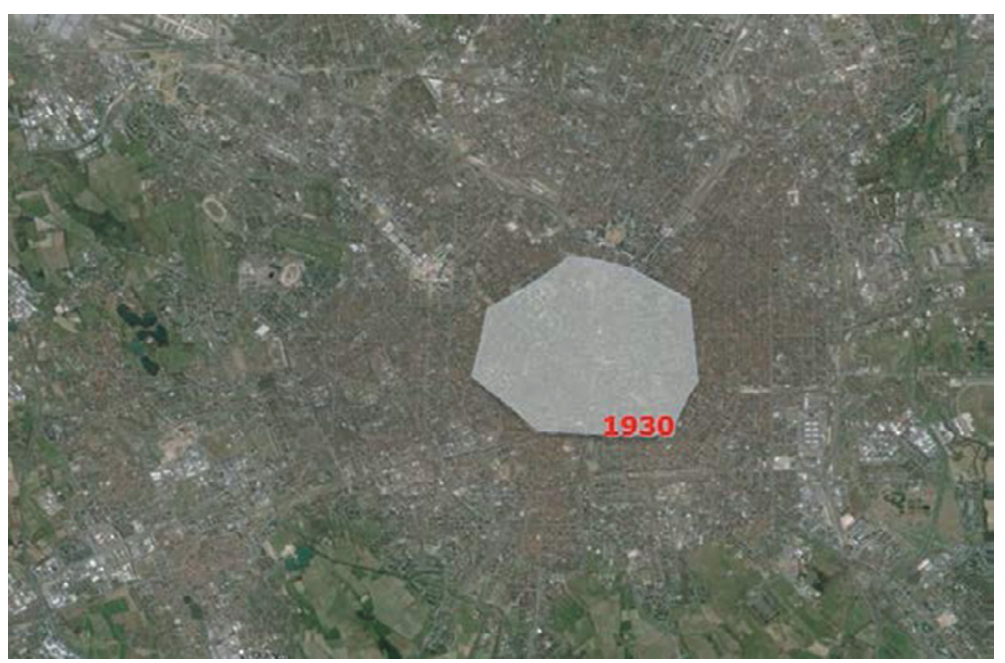

Figure 5: Size of Milano in 1930 compared with the present extension.

heavy rainfall waters, especially considering the number of minor rivers entering Milano; these discharges are negligible in dry weather, but to be considered during rainfalls.

\section{DESIGNED SOLUTIONS}

While the General Regulatory Plan, issued in 1953, still allowed the river Seveso to be covered, troubles were already experienced, and in 1954 the first works were already decided. As it will be seen in the next paragraphs, the dimensions of the designed solutions were increasing every year, until we arrive at the present time. 
In 2011, MM SpA carried out a study demonstrating the practical impossibility to improve the system Seveso-Naviglio della Martesana-Redefossi [4], i.e. the covered reach within the city of Milano, and therefore other solutions have to be carried out.

\subsection{The bypass (CSNO)}

In 1954, the municipality of Milano identified as indispensable the construction of a drainage channel north to the city to protect the northern districts (Fig. 6), with a length of around $34 \mathrm{~km}$. Discharge was estimated equal to $30 \mathrm{~m}^{3} / \mathrm{s}$; it was still the beginning of urbanization and at that time indications seemed overwhelming; the work was only completed in 1980, while in the period 1976-1979 Milano was flooded 25 times because of Seveso.

This solution, however, was not pacifically accepted by the people, because the waters are transported to the river Ticino, whose water quality is very good until its intersection with CSNO; on the contrary, water in CSNO is unacceptably polluted and therefore the quality of the water of the river Ticino becomes considerably worse from that point.

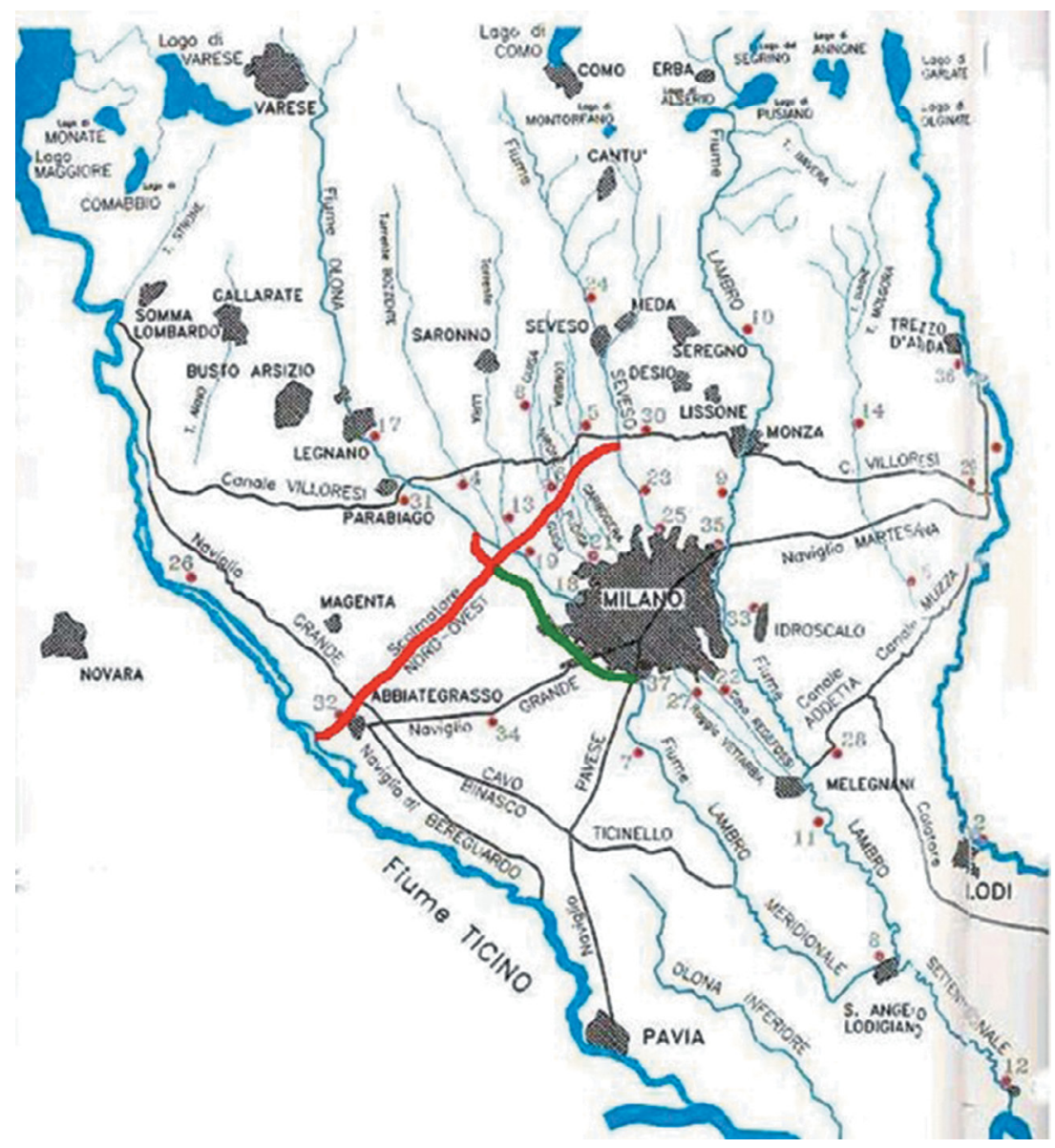

Figure 6: The hydrographic network in the area of Milano: red represents the CSNO and green the 'Deviatore Olona'. 
Moreover, in 1988, the municipality of Milano carried out a study that demonstrates the need to increase the discharge diverted from the river Seveso; in 1999, the works started to double the discharge diverted from Seveso (i.e. from the present $30 \mathrm{~m}^{3} / \mathrm{s}$ to the designed $60 \mathrm{~m}^{3} / \mathrm{s}$ ). These works are not fully concluded and therefore the discharge which is possible to divert from Seveso is still the original.

The costs to increase the capacity of CSNO have been estimated to be equal to 20 million Euros in 2008 [7]. However, as mentioned earlier, the works are not only to alleviate the problems of the river Seveso.

\subsection{The storage tanks in the catchment}

In the catchment, before the CSNO, the river is laminated and the request was that downstream the diversion in the CSNO the discharge in the Seveso river is equal to zero. As the wave of the event for the return period of 100 years has a volume of 6.7 million cubic meters, considering the discharge that can flow in the CSNO, the overall storage volume is estimated to be equal to 4.4 million cubic meters.

Analysing the urbanization of the catchment, which is very high, the only possibility to build these tanks is to dig quite deep (20-25 m below the ground level), and in areas to be equipped and returned to public enjoyment as green areas (see next paragraph). It is only through these works that it is possible to recover the necessary volumes (Fig. 7), since the possible solution to have these volumes by means of classic expansion of areas with levees and regulation artefacts would require such a strong 'de-urbanization' which is impossible to implement [8].

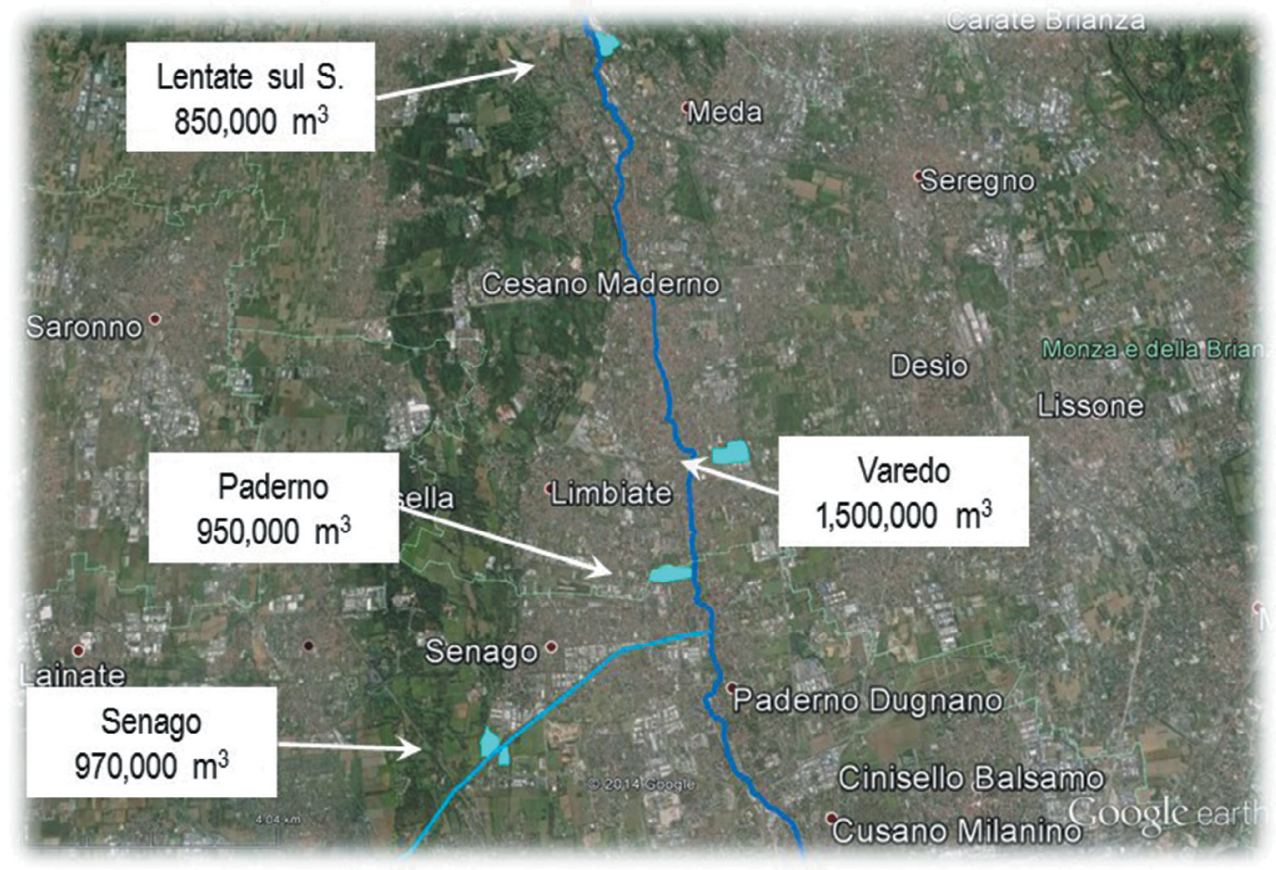

Figure 7: Position of the storage tanks under design or realization (total volume equal to $\left.4,270,000 \mathrm{~m}^{3}\right)$. 
Costs for the construction of the storage tanks are estimated as follows:

- Senago: 30 million Euros;

- Varedo: $\approx 28$ million Euros;

- Lentate sul Seveso: $\approx 18$ million Euros;

- Paderno Dugnano: $\approx 19$ million Euros.

Costs are more precise for the Senago tank as the design is at a more advanced stage [9], while the other tanks are still in a preliminary phase. Therefore, for Senago also maintenance costs have been estimated, and they are equal to 500,000 Euros per year. As mentioned earlier, the total costs for the construction of the four tanks are around 95 million Euros: this amount should decrease, since to assign public works a public bid has to be performed and discounts are expected.

\subsection{The storage tank in Milano}

Although in the design scenario the discharge downstream the CSNO is equal to zero, another storage tank has been designed to be positioned immediately upstream the covered reach of the river Seveso, in the northern part of Milano [10]. There are two essential reasons: first, to complete the whole design scenario still many years have to be expected, and a storage tank, even if not too large, can reduce the number of floods per year and therefore alleviate the discomfort of the people living in the area. The second reason is that, even when the design scenario is completed, the waters coming from the 36 surveyed overflow in the reach (Fig. 8) produce a total discharge which is superior to that conveyable by river Seveso in Milano.

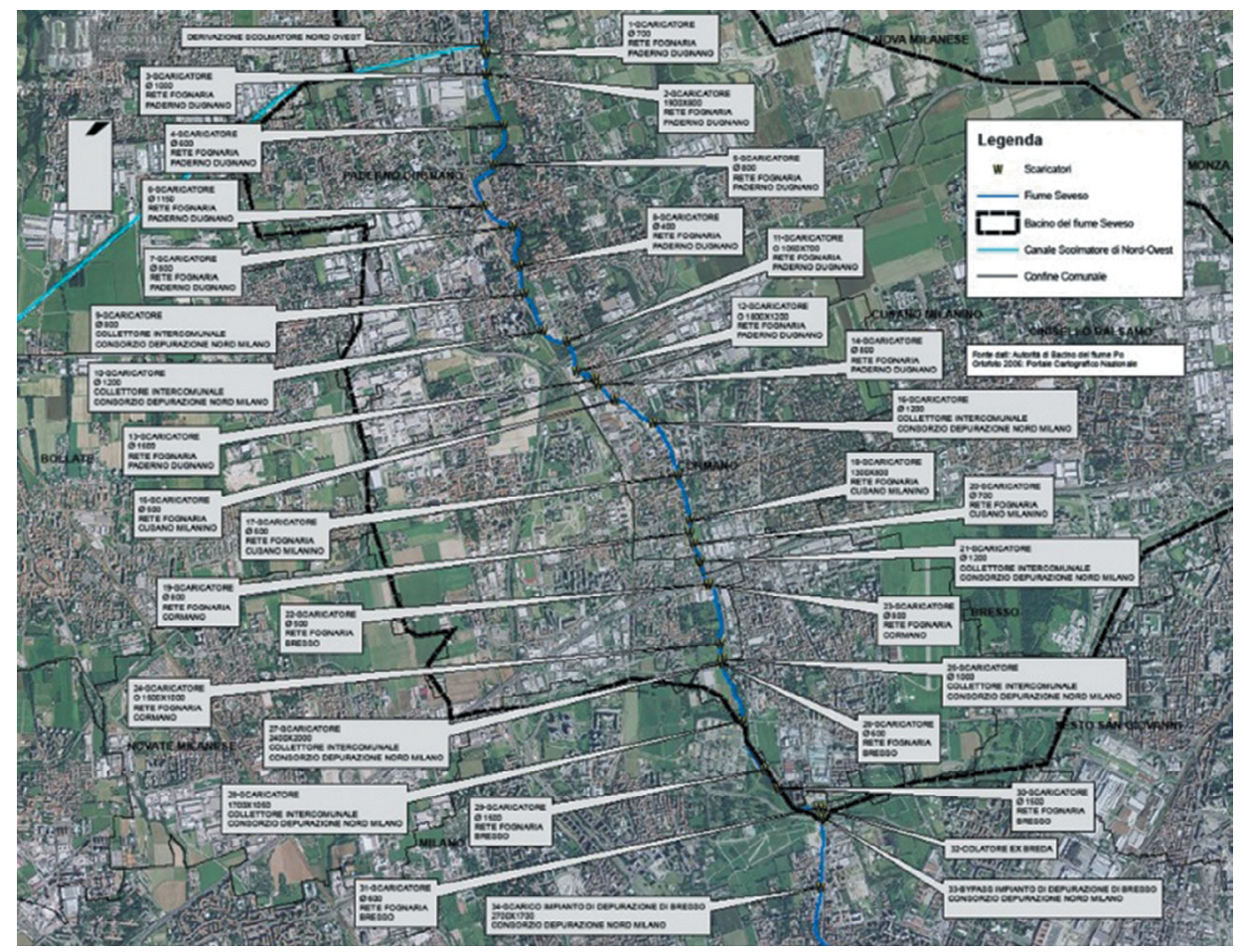

Figure 8: Surveyed combined sewer overflows in the reach between CSNO and Milano. 


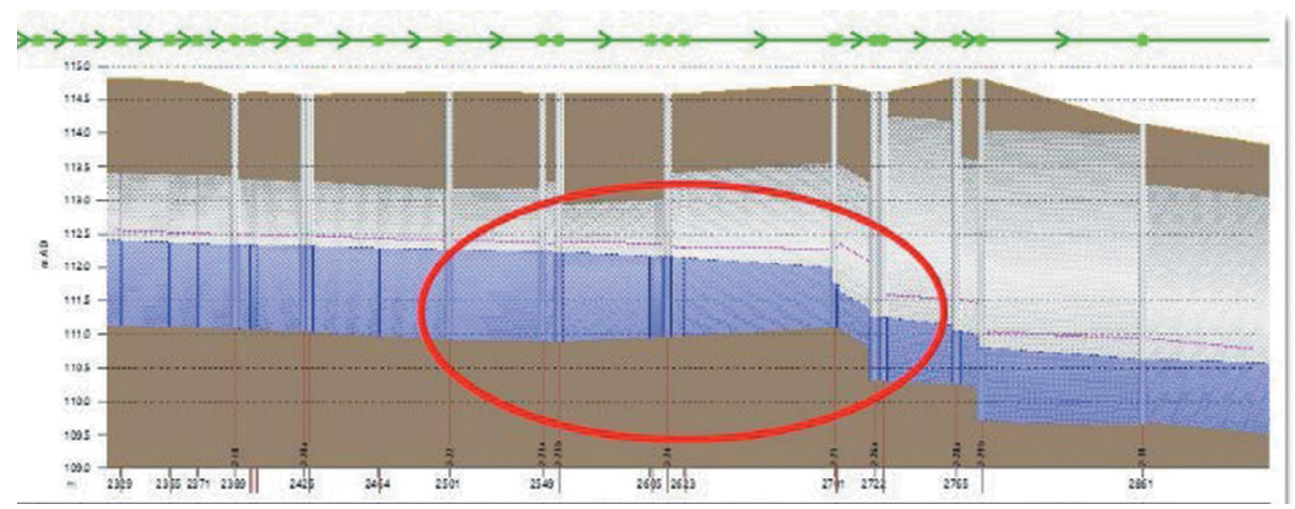

Figure 9: Mathematical model of part of the river Seveso; highlighted is a positive slope reach which should be rectified.

The reduction of the discharge should be imposed at the origin but, based on the survey of the overflows, it is only possible to design reductions in four positions. For the remaining 30 overflows there are no areas where to create tanks; therefore, it was proposed to build a storage tank of $250,000 \mathrm{~m}^{3}$ downstream the open reach of the river.

To estimate the discharge that can flow in the covered channel, a survey of the reach has been carried out and a mathematical model of the reach has also been built. The results show that a safe estimation is a value of the discharge equal to $30 \mathrm{~m}^{3} / \mathrm{s}$; actually the potential of the river is higher, but the tendency to have sedimentation and some critical points that should be rectified (Fig. 9) suggest the adoption of the above-mentioned value.

The carried out solution, now already designed and with the procedure to open a public competition close to the end, has the typical problems of the basins within a densely urbanized territory, the quality of the waters and the frequent opposition from the communities concerned (claims have been submitted to the court, so far unsuccessful). In order to limit these criticalities, the selected solution tries to reduce the negative impact on the territory.

The tank is made with a waterproof base and is provided with a partial filling of water taken from the first aquifer, thus creating a clear and clean water pond in 'normal' periods. When approaching the critical event (nowadays meteorology allows a sufficiently precise forecast of high-risk days), the pond will be quickly emptied, in few hours. That will allow to have the storage tank ready for use. At the end of the event, the water will be returned to Seveso, the bottom will be cleaned from any deposits and the area will return to be recreational. It has been estimated that for about 320 days a year, the basin will be clean and the area recreational, while for the remaining days the area will be used for the critical events.

Costs, only for the storage tank construction (and therefore excluding the works to rehabilitate the covered river), are estimated equal to 30 million Euros $+400,000$ Euros per year for maintenance.

\section{A NEW PARADIGMA IS REQUIRED}

The works to build the five storage tanks will have a global cost around 130 million Euros; moreover, extra costs are due to adequate CSNO and the covert reach of the river Seveso, which have not been estimated yet. In addition, there will be costs for maintenance of the 
tanks, and the - at least initial - opposition of the local communities. During the years, floods have occurred, again producing dozens of millions of Euros of damages.

It is difficult to estimate the advantages that the strong urbanization of the areas, during the so-called Italian economic boom, has produced for Milano and probably for the whole country. But in the authors' opinion this unregulated development has no other justification than the unconsciousness of the public administration of that time. Still in the authors' opinion, the same results in terms of development could have been reached considering the need for an appropriate defence from floods.

Absolute protection against floods is unachievable, and the construction of new storage tanks and bypasses has the advantage to produce immediate response to the request of protection, but they are non-flexible and prone to fail when the return period is overcome. Therefore, the approach to managing flood is to be more holistic resorting, mainly, to nonstructural measures like flood forecasting, early warning and, especially, spatial planning $[11,12]$. In the new approach to flood management, river cross-sections are widened by situating the main dikes further away from the river, or by lowering the river embankments. This process will lead to lower flood levels and to a new balance between present and foreseeable future spatial requirements for different land uses. Both people and water need the resource of floodplains and the new challenge is to design ways of sharing riverine room between floods and people. The 'Room for River and People' approach was met with the 'Making Space for Water' project [13] which set about an integrated portfolio of approaches, highlighting the importance of the non-structural measures, in particular of spatial planning.

Moreover, a more holistic view about the use of the resource 'water' is needed (Fig. 10): this implies plant interception and the application, when possible, of the concept of 'hydraulic

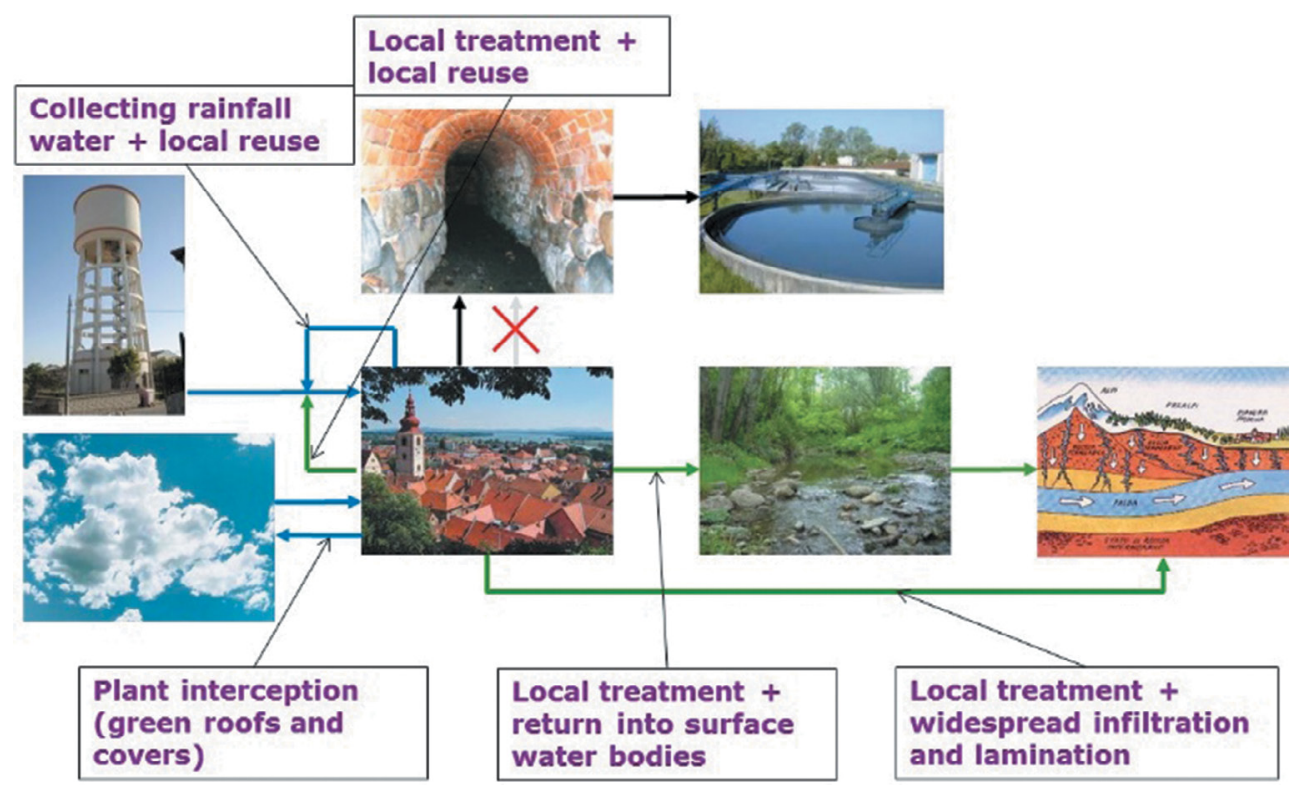

Figure 10: A more integrated relationship with the resource 'water', including reuse and quick and widespread restitution to the environment, is needed. 
invariance', that means the building of new constructions without increasing the flow rates and discharged volumes; and water management involves a fast and widespread restitution of the water to the environment, considering reuse, local treatment and widespread lamination.

\section{CONCLUSIONS}

In large cities, unregulated development produces frequent floods, whose consequences are high costs both for recovery after the events and for trying to produce effective solutions.

The story of the river Seveso in Milano has been briefly reconstructed; the river has been covered during the years, and every year it floods a quite large area in Milano, causing damages sometimes of high value. The solutions carried out so far are described, together with their costs, advantages and disadvantages.

As demonstrated with a practical and real example, these solutions are effective in the short term, but to cope with these hazards, it is imperative that human society adopts an effective flood risk management approach, which has to be in harmonious coexistence with water. To be effective, the hazard approach must be embodied in the broader context of integrated river basin planning and management, and flood must be regarded as one of the many issues involved in the appropriate management of a river basin.

Finally, a more integrated relationship with the resource 'water', which encompasses several components, including reuse and restitution to the environment as quickly as possible and widespread in the area, appears to be the best response to the various problems that can be encountered when dealing with this vital element.

\section{REFERENCES}

[1] Munich-Re, Flooding and Insurance. Münchner Rückversicherungs-Gesellschaft: Munich, 1997.

[2] De Wrachien, D., Mambretti, S. \& Schultz, B., Flood management and risk assessment in flood-prone areas: measures and solutions. Irrigation and Drainage, $60(2)$, pp. 229-240, 2011. DOI: 10.1002/ird.557.

[3] Qari, H.A., Jomoah, I. \& Mambretti, S., Flood management in highly developed areas: problems and proposed solutions. Journal of American Science, 10(3), pp. 6-15, 2014. DOI: $10.7537 /$ marsjas 100314.02 .

[4] MM SpA, Studio di fattibilità della sistemazione idraulica del torrente Seveso nella tratta compresa tra Palazzolo e Milano nell'ambito idrografico di pianura Lambro Olona, Technical Report, Milano, 2011 (in Italian).

[5] Felice Poggi, Idrografia nei dintorni di Milano nell'era romana, Milano, 1911 (in Italian).

[6] Gentile, A., Brown, M. \& Spadoni, G., Viaggio nel sottosuolo di Milano tra acque e canali segreti, Comune di Milano, Milano, 1990 (in Italian).

[7] La Montagna, G., The hydraulic safeguard of the city of Milan: the Canale Scolmatore di Nord-Ovest. Proceedings of 7th International Conference on Computer Simulation of Risk Analysis and Hazard Mitigation, Milano, pp. 693-702, 2010.

. [8] AIPO, Studio idraulico del Torrente Seveso, June 2011 (in Italian).

[9] AIPO, Vasca di laminazione sul fiume Seveso in comune di Senago - progetto definitivo, Ottobre 2014 (in Italian).

[10] MM SpA, Vasca di laminazione sul fiume Seveso in comune di Milano - progetto definitivo, Maggio 2017 (in Italian).

[11] Schultz, B., Irrigation, drainage and flood protection in a rapidly changing world. $I r$ rigation and Drainage, 50(4), pp. 261-277, 2001. DOI: 10.1002/ird.35. 
[12] Schultz, B., Flood management under rapid urbanisation and industrialisation in flood prone areas: a need for serious consideration. Irrigation and Drainage, 55(1), pp 3-8, 2006. DOI: 10.1002/ird.239.

[13] Department for Environment, Food and Rural Affairs, Making Space for Water Developing a New Government Strategy for Flood and Coastal Erosion Risk Management in England, London, 2004. 